\title{
I nterventions to prevent heart failure readmissions: The rationale for nurse-led heart failure programs
}

\author{
Devan Shan, Janice Finder, Daryl Dichoso, Patricia S. Lewis \\ Houston Methodist Sugar Land Hospital and Houston Methodist, United States \\ Correspondence: Patricia S. Lewis. Address: Houston Methodist Sugar Land Hospital, United States. \\ Email: pslewis@houstonmethodist.org \\ Received: June 8, 2014 \\ Accepted: August 6, 2014 \\ Online Published: August 31, 2014 \\ DOI : 10.5430/jnep.v4n11p23 \\ URL: http://dx.doi.org/10.5430/jnep.v4n11p23
}

\begin{abstract}
Background: Readmission to hospitals for heart failure is one of the greatest economic burdens on Medicare, and has become a major focus of healthcare reform. In an attempt to stem the overwhelming number of readmissions and improve heart failure outcomes, hospitals have employed multiple interventions. Nurse-led heart failure management programs have been an effective strategy in reducing hospital readmissions for heart failure.
\end{abstract}

Purpose: We conducted an integrative review of the literature that assessed the value of interventions to reduce heart failure readmission rates. We focused on the important role of nursing care in successfully implementing many of these interventions.

Methods: An integrative review of the literature was performed. A computerized search of PubMed, Cumulative Index to Nursing and Allied Health Literature (CINAHL), and Cochrane Library (reviews and clinical trials) was performed to locate articles published from 2004 to 2014. Key words used included "heart failure nursing”, "heart failure readmissions", "heart failure programs" and "interventions for heart failure readmission". Preference was placed on articles published in the last 10 years. Articles referenced by national heart failure guideline documents and expert consensus statements were given a high priority. Eighty-eight articles were screened initially by two reviewers; these were then screened to leave 40 relevant articles.

Conclusions: Several specific interventions have a proven favorable effect in reducing heart failure readmissions. These include optimal medical management, patient education and self-care instruction, and ensuring adequate post-discharge follow-up. Despite this knowledge there remains a wide variation of readmission rates across the United States. This may be partly due to the variability in the adequate implementation of interventions and/or the absence of a required number of interventions in different centers. Each single intervention in itself has only a very small beneficial effect. The implementation of several interventions is essential to produce a meaningful reduction in heart failure readmissions. The ability to successfully employ numerous interventions together may explain the promising results of structured nurse-led heart failure programs.

\section{Key words}

Heart failure readmissions, Heart failure program, Heart failure discharge teaching, Teach-back, Project BOOST, Project RED 


\section{I ntroduction}

Heart failure is the most common principal discharge diagnosis among patients over 65 years of age. Heart failure is also the third most costly diagnosis for Medicare as well as the leading cause of hospital admissions and readmissions in patients older than 65 years ${ }^{[1-3]}$.

Readmissions are common. Up to a fifth of patients hospitalized with heart failure are readmitted within 30 days and over half are readmitted within a year ${ }^{[4-6]}$. Over $50 \%$ of Medicare readmissions for heart failure have been classified as "unplanned or preventable”, costing $\$ 17$ billion ${ }^{[6]}$. This has led the Centers for Medicare and Medicaid Services (CMS) to use readmission rates as a publicly reported metric with planned lowering of reimbursements to hospitals that demonstrate excessive risk-standardized readmission rates ${ }^{[4]}$.

In response to these changes there has been great interest in reevaluating heart failure management during admission and post-discharge to reduce the readmission rates ${ }^{[1,2]}$. Many hospitals have introduced multidisciplinary teams to optimize the management of heart failure patients from admission through discharge, and into the outpatient setting ${ }^{[4,5]}$. Several key factors contributing to heart failure readmissions have been identified ${ }^{[7-9]}$. However, there remains considerable variation in the success rates of individual hospital programs to prevent heart failure readmissions across the U.S ${ }^{[7,8]}$.

The lack of success of some of these programs is likely due to multiple factors, such as the incomplete employment of interventions or the failure to employ an adequate number of interventions ${ }^{[10]}$. The potential impact of improving these deficiencies through specialized heart failure nursing is highlighted in this article. Indeed, the success of well-structured nurse-led programs to prevent heart failure readmissions has shown definite promise. These programs have shown that specialized and coordinated nursing care can significantly reduce heart failure readmissions ${ }^{[11-14]}$. One such program, Project RED (Re-Engineered Discharge), employs a nurse-discharge advocate in a key role to work with patients throughout the hospital stay. The nurse-discharge advocate arranges follow-up appointments, confirms medication reconciliation, and conducts patient education, as well as creating an individualized instruction booklet, which is sent to the primary care provider. Project RED also used a post-discharge call from a clinical pharmacist to reinforce the discharge plan and review medications. In a randomized study of 749 heart failure patients, the implementation of Project RED decreased hospital readmissions by $30 \%$ within the first 30 days of discharge. The results for the control group versus the intervention group were 0.314 vs. 0.451 visits per person per month, respectively $(p=.009)^{[11]}$. The marked success of this program led to a partnership between the Agency for Healthcare Research and Quality (AHRQ) and Boston University Medical Center, the developers of Project RED, to help disseminate the program across the country ${ }^{[12]}$.

Project BOOST (Better Outcomes by Optimizing Safe Transitions) is another care transition program that has developed a toolkit that includes medication reconciliation forms, a checklist for discharge patient education, and a checklist for post-discharge continuity checks (see Table 1). Initial data from 11 hospitals participating in the project BOOST showed an absolute $2 \%$ reduction in 30 -day readmission rates compared with site-matched control units ${ }^{[13]}$.

Despite the success of these programs, there remains no universally accepted or standardized approach to heart failure nursing programs. Moreover, the optimal use of interventions to reduce heart failure readmissions remains incompletely understood and continues to be an area of intense research.

This article will review recent data on specific interventions that have been found to be important in reducing heart failure readmission. We will also attempt to further elucidate why precisely coordinated specialized nursing can achieve significant improvements in heart failure outcome.

\section{Interventions to reduce heart failure readmissions}

Three separate phases of heart failure management are now widely accepted ${ }^{[5]}$ : 
1) Pre-discharge: Consisting of patient education, medication reconciliation, discharge planning, and scheduling of a follow-up appointment.

2) Transition of care (between in- and out- patient settings): Bridging interventions with patient-centered discharge instruction.

3) Post-discharge: Post-discharge follow-up telephone calls, patient-activated hotlines, timely communication with ambulatory providers, timely ambulatory provider follow-up and post-discharge home visits.

Table 1. Project BOOST Checklist sample

\begin{tabular}{|c|c|c|c|}
\hline & Process & & \\
\hline Data Elements & $\begin{array}{l}\text { Discharge } \\
\text { Summary }\end{array}$ & $\begin{array}{l}\text { Patient } \\
\text { Instructions }\end{array}$ & $\begin{array}{l}\text { Communication to follow-up } \\
\text { clinician on day of discharge }\end{array}$ \\
\hline Presenting problem that precipitated hospitalization & $\mathrm{x}$ & $\mathrm{x}$ & $\mathrm{x}$ \\
\hline Key findings and test results & $\mathrm{x}$ & & $\mathrm{x}$ \\
\hline Final primary and secondary diagnoses & $\mathrm{x}$ & $\mathrm{x}$ & $\mathrm{x}$ \\
\hline Brief Hospital Course & $\mathrm{x}$ & & $\mathrm{x}$ \\
\hline $\begin{array}{l}\text { Condition at discharge, including functional status } \\
\text { and cognitive status if relevant }\end{array}$ & $\begin{array}{l}\mathrm{x} \text { - functional status } \\
\mathrm{o}-\text { cognitive status }\end{array}$ & & \\
\hline Discharge destination (and rationale if not obvious) & $\mathrm{x}$ & & $\mathrm{x}$ \\
\hline \multicolumn{4}{|l|}{ Discharge medications } \\
\hline Written schedule & $\mathrm{x}$ & $\mathrm{x}$ & $\mathrm{x}$ \\
\hline $\begin{array}{l}\text { Include purpose and cautions (if appropriate) for each } \\
\text { Comparison with preadmission medications } \\
\text { (new, changes in dose/freq. unchanged, "meds } \\
\text { should no longer take”) }\end{array}$ & o & $\mathrm{x}$ & o \\
\hline
\end{tabular}

Note. Project BOOST ${ }^{\circledR}$ (Better Outcomes by Optimizing Safe Transitions). www.hospitalmedicine.org/BOOST. Society of Hospital Medicine, 2014. All rights reserved

This taxonomy allows separation into areas that involve disease management, case management, and discharge-planning interventions. Structured nursing involvement is vital for successful completion of all three of these phases of heart failure management. In particular, the first two phases, "pre-discharge” and "transition of care” interventions ${ }^{[15-20]}$, are highly dependent upon an organized nursing team within the hospital. The "post-discharge phase" includes approaches such as home-care visits. The value of this intervention has been the subject of a recent comprehensive review ${ }^{[21]}$.

It is likely the several interventions throughout all three of these phases of heart failure management are required to produce significant changes in heart failure readmission rates ${ }^{[9,15]}$. The importance of the cumulative effect provided by a series of successful multiple interventions have been well demonstrated in a recent study by Bradley et al. ${ }^{[9]}$. These investigators surveyed almost 600 hospitals and found six independent strategies that were associated with statistically significant lower hospital risk-standardized 30-day readmission rates. These strategies are as follows:

1) Partnering with community physicians or physician groups to reduce readmission rates

2) Partnering with local hospitals to reduce readmissions

3) Having nurses responsible for medication reconciliation

4) Arranging follow-up appointments before discharge

5) Having a process in place to send all discharge paper or electronic summaries directly to the patient's primary physician

6) Assigning staff to follow up on test results that return after the patient is discharged. 
The isolated impact of each individual strategy conferred less than half a percentage point reduction in "risk-standardized 30-day readmission rates" ${ }^{[9]}$. Thus it appears that the cumulative effect of many separate interventions is a prerequisite for clinically, and economically, meaningful reductions in heart failure readmissions.

However, the difficulty in reliably implementing interventions to reduce heart failure readmissions continues to be a major obstacle. Indeed, Bradley et al. found less than 30\% of hospitals implemented the majority of the six strategies and only $7 \%$ implemented all six. It is also interesting to note that the value of each individual intervention appeared proportionately greater in hospitals that used a larger number of the strategies ${ }^{[9]}$. Thus, it is tempting to speculate that more comprehensive heart failure programs may achieve a more effective "heart failure culture" leading to better implementation of each individual strategy. Conversely, a useful intervention that is imperfectly employed is likely to have its beneficial effect underestimated or overlooked. Thus, we would expect focused nursing care to enhance the effect of not only well established interventions, but may also reveal the importance of newer interventions that are currently of uncertain benefit.

\section{Pre-discharge}

Successful heart failure programs initiate interventions early in the pre-discharge phase (which commences immediately upon admission). For example, the Project RED heart failure program designated a nurse discharge advocate who initiated interventions within the first 24 hours of admission. This key individual completed numerous interventions, including medication reconciliation, communicating with hospital physicians, and patient education. In addition, the nurse discharge advocate explained medication plans to patients and generated an individualized patient instruction booklet. The success of structured nurse-led heart failure programs may also stem from the fact that even small enhancements of important nurse-dependent interventions may be efficacious.

For example, precise nursing will help ensure the early introduction of evidence-based heart failure therapy and confirm that the discharge medical regimen meets national guideline standards. Moreover, patient-centered education by nurses throughout the pre-discharge phase and follow-up post-discharge will improve patient compliance ${ }^{[22-25]}$. Also, the impact of even simple interventions conducted well during the pre-discharge phase may produce considerable improvements in the outcome ${ }^{[26,27]}$. For example, marked improvements in patient compliance have been reported by use of a nurse-generated "user-friendly" patient discharge form, combined with telephone follow-up by a nurse. In a randomized series of 122 patients, only $14.9 \%$ of patients receiving this intervention failed to follow up within 21 days, compared to $40.8 \%$ of the concurrent controls. Furthermore, only $11.5 \%$ of the recommended outpatient workups in the intervention group were not completed compared with over $30 \%$ in the control group who failed to complete workups ${ }^{\text {[27] }}$.

Improvements in patient compliance, coupled with more reliable implementation of evidence-based heart failure therapy, can translate into markedly improved outcomes. It is well accepted that guideline-recommended heart failure therapy reduces heart failure readmissions, and that patient adherence to long-term therapy significantly reduces mortality ${ }^{[29-33]}$.

Nurse-led heart failure programs can improve the implementation of evidence-based therapy in multiple ways. Specialized nursing facilitates better coordination of medical therapy between hospital physicians, outpatient physicians and their patients ${ }^{[11,13,14,31]}$.

In fact, recent studies have measured the magnitude of the benefit conferred by in-hospital initiation of evidence-based heart failure therapy. These data may allow us to gain a somewhat more quantitative appreciation of the benefit achieved through better implementation of evidence-based heart failure drug therapy by focused heart failure nursing care.

One such study utilized the IMPROVE-heart-failure registry to examine outcomes in 4000 heart failure patients ${ }^{\text {[30] }}$. Patient-centered educational efforts about heart failure reduced the risk of death by $27 \%$ in this series of patients. It is interesting to note that a significant incremental benefit was seen with the serial addition of up to four to five therapies. For 
example, beta blockers, ACE inhibitors/ARBs, and ICDs, when combined with patient-centered heart failure education, reduced the risk of death at two years by $81 \%$ [30].

We hypothesize that such a marked benefit can only be achieved by careful attention to detail performed by wellcoordinated specialized nursing care. Knowledgeable heart failure nursing may also be expected to help with the optimization of other parameters of heart failure treatment, including volume status, weights, vital signs, electrolyte balance and renal function. Early attention to these indices and improved communication with hospital physicians will also decrease the risk of heart failure readmissions.

It should be noted that the "pre-discharge phase" encompasses the entire admission period. This time period provides an important window of opportunity to complete other valuable interventions such as mitigating non-medical factors (e.g., support at home) that may increase the risk for readmission ${ }^{[13]}$.

\section{Transition of care}

“Transition of care” interventions (see Figure 1) are aimed specifically at avoiding poor clinical outcomes arising from uncoordinated and lapses of care during transfer between two different locations. This key strategy to reduce heart failure readmissions has attracted much interest as one of the principal targets of multidisciplinary heart failure programs ${ }^{[11,13,14]}$. It has been defined as "a broad range of time-limited services designed to ensure health care continuity, avoid preventable poor outcomes among at-risk populations, and promote the safe and timely transfer of patients from one care setting to another" ${ }^{[5]}$.

In fact, national performance measures have now recommended several interventions, largely driven by nursing staff that improve the "transition of care" ${ }^{[8]}$. The growing interest in optimizing "care transition" is further underscored by several national performance measures directly addressing the standard of care for discharging heart failure patients. For example, in 2011, the ACC/AHA/AMA Performance Consortium ${ }^{[22]}$ added a "documented post-discharge appointment" to the list of heart failure performance measures. The elements of the documentation were also very exact and require location, date, and time for a follow-up office visit or home health care visit.

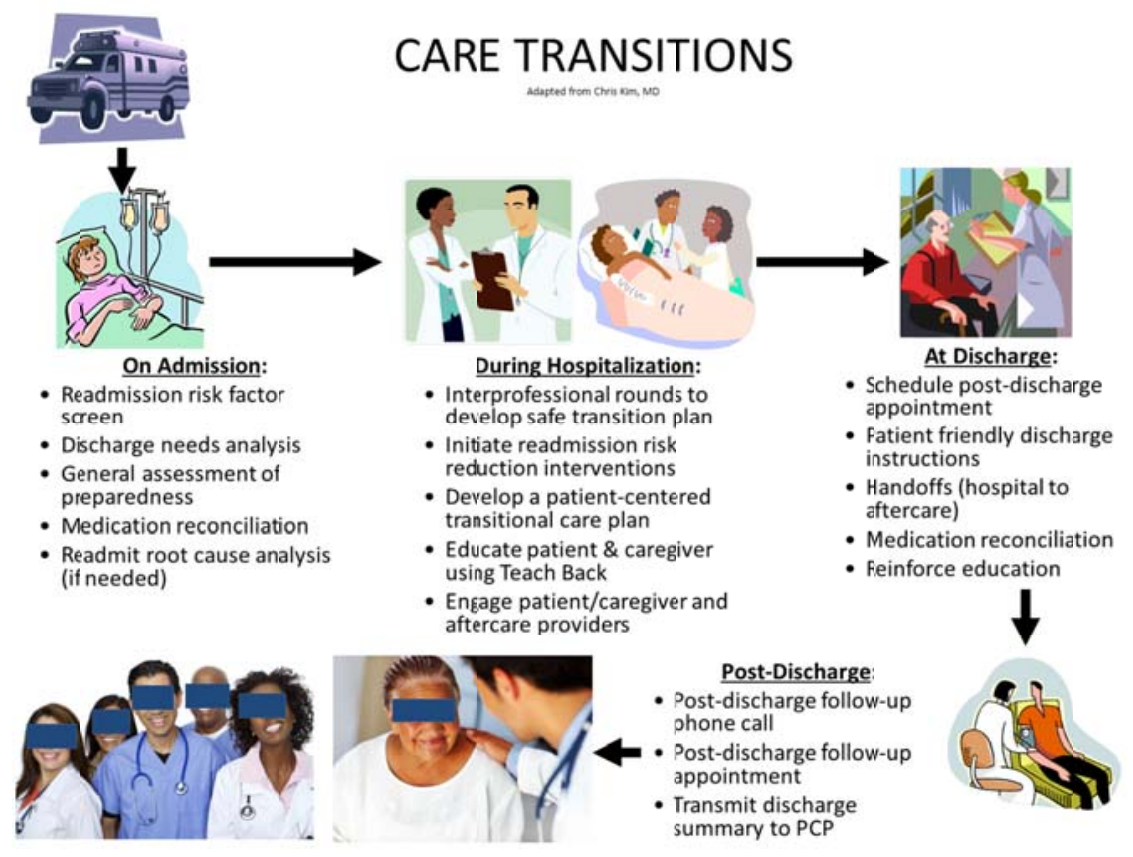

Figure 1. Care Transition 
Structured heart failure programs that already follow many of these recommendations have shown improved patient follow-up post-discharge. For example, in a series of 749 patients, Project RED heart failure investigators found that "patient reported" physician follow-up 30 days post-discharge was $62 \%$ in the intervention group, compared with $44 \%$ of the control group.

Recently the AHA, ACC, and the Heart Failure Society guidelines have placed a strong emphasis on "post discharge systems of care" ${ }^{\text {[33] }}$. The recommendations specify the following: activity level, diet, discharge medications, a follow-up appointment, weight monitoring and what to do if symptoms worsen. Furthermore, the Joint Commission performance measures mandate that all patients with heart failure should receive comprehensive written discharge instructions, or other educational materials, that address the topics listed above ${ }^{[1]}$. These measures are publicly reported by hospitals. Elements of the education plan involve both teaching content areas and self-management behaviors ${ }^{[34,35]}$.

Patient education, through teach-back and patient counseling, is being increasingly used in heart failure programs (see Figure 2) ${ }^{[13]}$. This intervention is also supported by a position statement from the AHA ${ }^{[33]}$. However, significant barriers to patient self-care education are often present, such as cognitive impairment ${ }^{[36,37]}$, depression ${ }^{[38]}$, and poor health literacy ${ }^{[13]}$.

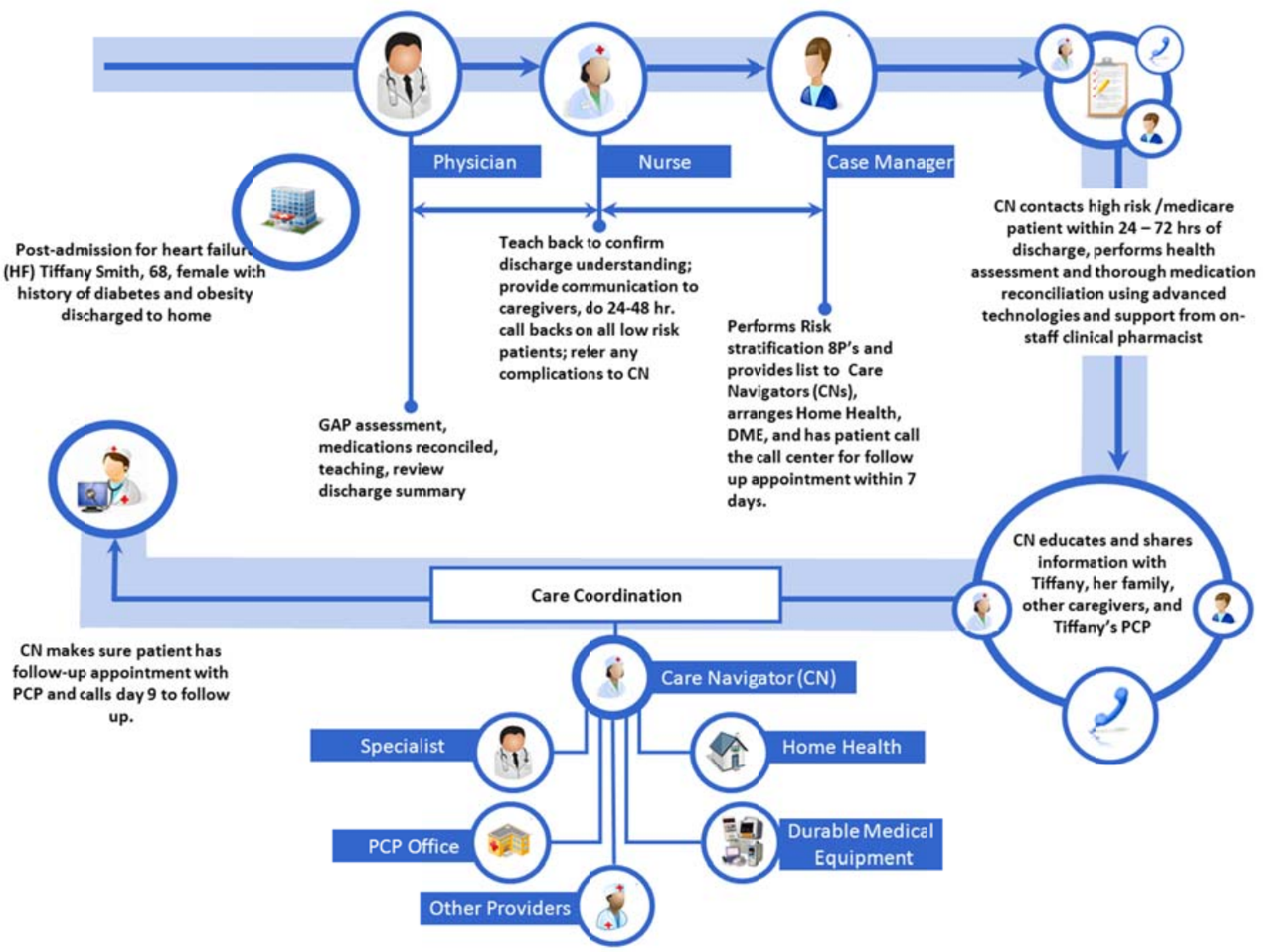

Figure 2. Care Coordination

Also, despite the above recommendations, “care transition” remains poorly implemented ${ }^{[10]}$. This problem has been well illustrated in a recent study by Bradley et al. ${ }^{[10]}$, who examined responses from 537 hospitals enrolled in the Hospital to Home $(\mathrm{H} 2 \mathrm{H})$ quality improvement program. These investigators reported the implementation of 10 key interventions across three separate areas ${ }^{[1]}$ : quality improvement efforts and performance monitoring regarding readmission ${ }^{[2]}$, medication management, and ${ }^{[3]}$ discharge and follow-up procedures. It was found that less than half of hospitals had 
partnered with community physicians. Furthermore, less than $30 \%$ of hospitals consistently linked inpatient and outpatient prescription records electronically. In addition, only a quarter of the hospitals stated that they always sent a discharge summary directly to the patient's primary medical doctor. Overall, 4.8 of 10 key practices were implemented, with less than $3 \%$ of hospitals employing all 10 practices. Thus, even if the specified targets of care transition are delineated, the health care environment required to successfully adopt them may be absent. In contrast, heart failure programs, which have effectively mastered "care transition", have shown significant reductions in readmissions ${ }^{[11,14]}$.

Important components of Care Transition include the following ${ }^{[13,39]}$ :

- $\quad$ Medications reconciled with preadmission list

- Medication use/side effects reviewed using teach-back with patients/caregivers

- Teach-back used to confirm patient/caregiver understanding of diagnosis, prognosis, self-care requirements, and symptoms of complications requiring immediate medical attention (see Figure 3)

- Action plan for management of symptoms/side effects/complications requiring medical attention established and shared with patient/caregiver using teach-back

- Discharge education plan completed and provided to patient/caregiver at discharge

- $\quad$ Discharge communication provided to post-hospitalization care providers

- Documented receipt of discharge information from principal care providers

- Direct communication with principal outpatient provider at discharge

- Telephone contact arranged within 72 hours of discharge in order to assess the patient's condition, and adherence to the discharge plan, and to reinforce follow-up

- Medication safety discussion after discharge

Preparation for care transition should ideally start at the time of admission and be developed throughout the hospitalization ${ }^{[21]}$. In addition to facilitating timely interventions, this approach also allows the assessment of the risk for readmission well before discharge. This can be performed by identifying high-risk markers for readmission ${ }^{[40]}$, which may include multiple hospitalizations in the last 6 months (the strongest single risk factor), the absence of a caregiver, cognitive impairment, and poor health literacy. Identifying patients at high-risk for readmission will help optimize the distribution of resources and possibly ameliorating prior to discharge.

\section{Questions to Engage the Patient in Teach-Back}

- "I want to make sure I explained everything clearly. Can you explain it back to me so I'm sure I did?"

- "What will you tell your spouse about the changes the doctor made to your prescribed medications?"

- "I want to make sure I did a good job of teaching you today about ............... Can ycu please tell me in your own words...................?"

- "We've gone over a lot of information, in your own words, can your review with me what we talked about?"

Figure 3. Questions to Engage the Patient in Teach-back

For example, unrecognized cognitive impairment has been reported to be present in as many as $50 \%-70 \%$ of elderly heart failure patients ${ }^{[37]}$. Even mild cognitive impairment may negate or dilute the benefit of in-hospital self-care education. This is underscored by a recent series of 125 patients with mild cognitive impairment admitted with heart failure who 
received pre-discharge patient-centered education. The investigators found, that at 30 days post-discharge, there was no significant change in the ability to self-care. Moreover, there was no difference in readmission rates between the intervention and non-intervention groups ${ }^{[36]}$. Thus, identification of significant cognitive impairment should change the approach to patient education with a shift in focus on educating caregivers and family members. Without an appreciation of such barriers to interventions, nursing time and resources will be misapplied.

Thus, care transition is a specialized time-consuming process and requires a deep understanding of the obstacles that may diminish the effect of certain interventions. Indeed, the success achieved by several structured heart failure programs underscores the time investment required to optimize care transition as well as pre-discharge care.

\section{Conclusions}

Several nurse-led interventions have emerged as extremely valuable in reducing heart failure readmissions. These include the following: patient education and self-care instruction (both inpatient and outpatient), case management, multidisciplinary outpatient care, telephone support, as well as improving links and planning community care at hospital discharge. The successful implementation of multiple interventions is essential to produce a significant reduction in heart failure readmissions. The majority of these interventions is "nurse-driven", and can most efficaciously be implemented in structured nurse-led heart failure programs. It is likely that many heart failure programs will continue to underperform without the use of coordinated care from specialized heart failure nurses.

\section{References}

[1] Bonow RO, Ganiats TG, Beam CT, Blake K, Casey DE Jr, Goodlin SJ, et al. American College of Cardiology Foundation; American Heart Association Task Force on Performance Measures; American Medical Association-Physician Consortium for Performance Improvement: ACCF/AHA/AMA-PCPI 2011 performance measures for adults with heart failure: a report of the American College of Cardiology Foundation/American Heart Association Task Force on Performance Measures and the American Medical Association-Physician Consortium for Performance Improvement. Circulation. 2012 May 15; 125(19): 2382-401. PMid:22528524 http://dx.doi.org/10.1161/CIR.0b013e3182507bec

[2] Agency for Healthcare Research and Quality. Heart failure (HF): hospital 30-day, all cause, risk-standardized mortality rate (RSMR) following HF hospitalization. 2011. July 2, 2012. Available from:

http://www.qualitymeasures.ahrq.gov/content.aspx?id=27441

[3] Kocher RP, Adashi EY. Hospital readmissions and the Affordable Care Act: paying for coordinated quality care. JAMA. 2011; 306(16): 1794-1795. PMid:22028355 http://dx.doi.org/10.1001/jama.2011.1561

[4] Evidence-based Practice Center Systematic Review Protocol Project Title: Transitional Care Interventions To Prevent Heart Failure Readmissions: www.effectivehealthcare.ahrq.gov. Published online: June 10, 2013.

[5] Hansen LO, Young RS, Hinami K, Leung A, Williams MV. Interventions to reduce 30-day rehospitalization: a systematic review.. Reducing 30-day rehospitalization. Ann Intern Med. 2011 Oct 18; 155(8): 520-8. PMid:22007045 http://dx.doi.org/10.7326/0003-4819-155-8-201110180-00008

[6] Rosamond W, Flegal K, Furie K, Go A, Greenlund K, Haase N, et al. Heart disease and stroke statistics--2008 update: a report from the American Heart Association Statistics Committee and Stroke Statistics Subcommittee. American Heart Association Statistics Committee and Stroke Statistics Subcommittee. Circulation. 2008 Jan 29; 117(4): e25-146. PMid:18086926 http://dx.doi.org/10.1161/CIRCULATIONAHA.107.187998

[7] http://www.cms.gov/Medicare/Quality-Initiatives-Patient-Assessment-Instruments/HospitalQualityInits/Downloads/HospitalCh artBook2011.pdf

[8] Joynt KE, Jha AK. Who has higher readmission rates for heart failure, and why? Implications for efforts to improve care using financial incentives. Circ Cardiovasc Qual Outcomes. 2011; 4: 53-59. PMid:21156879 http://dx.doi.org/10.1161/CIRCOUTCOMES.110.950964

[9] Bradley EH, Curry L, Horwitz LI, Sipsma H, Wang Y, Walsh MN, et al. Strategies associated with 30-day readmission rates for patients with heart failure. Hospital Circ Cardiovasc Qual Outcomes. 2013 Jul 1; 6(4): 444-50. PMid:23861483 http://dx.doi.org/10.1161/CIRCOUTCOMES.111.000101 
[10] Bradley EH, Curry L, Horwitz LI, Sipsma H, Thompson JW, Elma M, et al. Contemporary evidence about hospital strategies for reducing 30-day readmissions: a national study. J Am Coll Cardiol. 2012 Aug 14; 60(7): 607-14. PMid:22818070 http://dx.doi.org/10.1016/j.jacc.2012.03.067

[11] Jack BW, Chetty VK, Anthony D, et al. A reengineered hospital discharge program to decrease rehospitalization: a randomized trial. Ann Intern Med. 2009; 150: 178-87. PMid:19189907 http://dx.doi.org/10.7326/0003-4819-150-3-200902030-00007

[12] Internet Citation: Selected References: Project RED (Re-Engineered Discharge) Training Program. August 2011. Agency for Healthcare Research and Quality, Rockville, MD.

[13] Hansen LO, Greenwald JL, Budnitz T, Howell E, Halasyamani L, Maynard G, et al. Project BOOST: effectiveness of a multihospital effort to reduce rehospitalization. J Hosp Med. 2013 Aug; 8(8): 421-7. PMid:23873709 http://dx.doi.org/10.1002/jhm.2054

[14] McCarthy, Douglas. University of California, San Francisco Medical Center: Reducing Readmissions Through Heart Failure Care Management Fund. November 14, 2012.

[15] http://partnershipforpatients.cms.gov/p4p_resources/tsp-preventablereadmissions/toolpreventablereadmissions.html

[16] Clancy C. Re-engineering hospital discharge: A protocol to improve patient safety reduce costs, and boost patient satisfaction. Am J Med Qual. 2009 Jul-Aug; 24: 344-46. PMid:19502567 http://dx.doi.org/10.1177/1062860609338131

[17] Hospital Nursing and 30-Day Readmissions Among Medicare Patients With Heart Failure, Acute Myocardial Infarction, and Pneumonia. McHugh MD, MC Med Care. 2013; 51: 52-59. PMid:23151591 http://dx.doi.org/10.1097/MLR.0b013e3182763284

[18] Greenwald J, Jack B. Preventing the preventable: reducing rehospitalizations through coordinated, patient-centered discharge processes. Prof Case Manag. 2009 May-Jun; 14: 135-40. PMid:19474639 http://dx.doi.org/10.1097/NCM.0b013e318198d4e1

[19] Svendsen A. Heart failure: an overview of consensus guidelines and nursing implications. Can J Cardiovasc Nurs. 2003; 13(2): 30-4. PMid:12802836

[20] Relationship between early physician follow-up and 30-day readmission among Medicare beneficiaries hospitalized for heart failure. Hernandez AF, Greiner MA, Fonarow GC, Hammill BG, Heidenreich PA, Yancy CW, Peterson ED, Curtis LH. JAMA. 2010; 303: 1716-1722. PMid:20442387 http://dx.doi.org/10.1001/jama.2010.533

[21] Transitional care programs improve outcomes for heart failure patients: an integrative review. Stamp KD, Machado MA, Allen NA. J Cardiovasc Nurs. 2014 Mar-Apr; 29(2): 140-54. PMid:23348223 http://dx.doi.org/10.1097/JCN.0b013e31827db560

[22] Bonow RO, Ganiats TG, Beam CT, Blake K, Casey DE Jr, Goodlin SJ, et al. American College of Cardiology Foundation; American Heart Association Task Force on Performance Measures; American Medical Association-Physician Consortium for Performance Improvement: ACCF/AHA/AMA-PCPI 2011 performance measures for adults with heart failure: a report of the American College of Cardiology Foundation/American Heart Association Task Force on Performance Measures and the American Medical Association-Physician Consortium for Performance Improvement. Circulation. 2012 May 15; 125(19): 2382-401. PMid:22528524 http://dx.doi.org/10.1161/CIR.0b013e3182507bec

[23] Greenwald J, Jack B. Preventing the preventable: reducing rehospitalizations through coordinated, patient-centered discharge processes. Prof Case Manag. 2009 May-Jun; 14: 135-40. PMid:19474639 http://dx.doi.org/10.1097/NCM.0b013e318198d4e1

[24] Harrison PL, Hara PA, Pope JE, Young MC, Rula EY. The impact of postdischarge telephonic follow-up on hospital readmissions. Popul Health Manag. 2011; 14: 27-32. PMid:21090991 http://dx.doi.org/10.1089/pop.2009.0076

[25] Svendsen A. Heart failure: an overview of consensus guidelines and nursing implications. Can J Cardiovasc Nurs. 2003; 13(2): 30-4. PMid:12802836

[26] Hernandez AF, Greiner MA, Fonarow GC, Hammill BG, Heidenreich PA, Yancy CW, et al. Relationship between early physician follow-up and 30-day readmission among Medicare beneficiaries hospitalized for heart failure. JAMA. 2010; 303: 1716-1722. PMid:20442387 http://dx.doi.org/10.1001/jama.2010.533

[27] Balaban et al. Redefining and redesigning hospital discharge to enhance patient care: a randomized control study. The Journal of General Internal Medicine. 2008; 23(8): 1228-1233. PMid:18452048 http://dx.doi.org/10.1007/s11606-008-0618-9

[28] Uptitration of renin-angiotensin system blocker and beta-blocker therapy in patients hospitalized for heart failure with reduced versus preserved left ventricular ejection fractions. Verbrugge FH, Duchenne J, Bertrand PB, Dupont M, Tang WH, Mullens W. Am J Cardiol. 2013 Dec 15; 112(12): 1913-20. PMid:24286620 http://dx.doi.org/10.1016/j.amjcard.2013.08.013

[29] Fonarow GC, Albert NM, Curtis AB, et al. Incremental reduction in risk of death associated with use of guideline-recommended therapies in patients with heart failure: a nested case-control analysis of IMPROVE HF. J Am Heart Assoc Cardiovasc Cerebrovasc Dis. 2012; 1(1): 16-26.

[30] Fonarow GC, Abraham WT, Albert NM, Stough WG, Gheorghiade M, Greenberg BH, et al. OPTIMIZE-HF Investigators and Hospitals. Association between performance measures and clinical outcomes for patients hospitalized with heart failure. JAMA. 2007 Jan 3; 297(1): 61-70. PMid:17200476 http://dx.doi.org/10.1001/jama.297.1.61 
[31] Gardetto NJ, Carroll KC.Management strategies to meet the core heart failure measures for acute decompensated heart failure: a nursing perspective. Crit Care Nurs Q. 2007 Oct-Dec; 30(4): 307-20. PMid:17873567

http://dx.doi.org/10.1097/01.CNQ.0000290364.57677.56

[32] Hernandez AF, Hammill BG, O'Connor CM, Schulman KA, Curtis LH, Fonarow GC. Clinical effectiveness of beta-blockers in heart failure: findings from the OPTIMIZE-HF (Organized Program to Initiate Lifesaving Treatment in Hospitalized Patients with Heart Failure) Registry. J Am Coll Cardiol. 2009 Jan 13; 53(2): 184-92. PMid:19130987 http://dx.doi.org/10.1016/j.jacc.2008.09.031

[33] Pamela N. Peterson, Susan J. Pressler, Douglas D. Schocken, David J. Whellan, Kathleen L. Grady, Michelle Z. Gurvitz, et al. State of the science: promoting self-care in persons with heart failure: a scientific statement from the American Heart AssociationLindenfeld. Circulation. 2009; 120: 1141-1163. PMid:19720935 http://dx.doi.org/10.1161/CIRCULATIONAHA.109.192628

[34] Makaryus, A., \& Friedman, E. Patients' understanding of their treatment plans and diagnosis at discharge. The Mayo Clinic Proceedings. 2005; 80(8): 991-994. PMid:16092576 http://dx.doi.org/10.4065/80.8.991

[35] Boyde M, Turner C, Thompson DR, Stewart S. J. Educational interventions for patients with heart failure: a systematic review of randomized controlled trials. Cardiovasc Nurs. 2011 Jul-Aug; 26(4): E27-35. PMid:21076308 http://dx.doi.org/10.1097/JCN.0b013e3181ee5fb2

[36] Davis KK, Mintzer M, Dennison Himmelfarb CR, Hayat MJ, Rotman S, Allen J. Targeted intervention improves knowledge but not self-care or readmissions in heart failure patients with mild cognitive impairment. Eur J Heart Fail. 2012 Sep; 14(9): 1041-9. PMid:22736737 http://dx.doi.org/10.1093/eurjhf/hfs096

[37] Hawkins LA, Kilian S, Firek A, Kashner TM, Firek CJ, Silvet H. Cognitive impairment and medication adherence in outpatients with heart failure. Heart Lung. 2012 Nov-Dec; 41(6): 572-82. PMid:22784869 http://dx.doi.org/10.1016/j.hrtlng.2012.06.001

[38] Sohani ZN1, Samaan Z. Does depression impact cognitive impairment in patients with heart failure? Cardiol Res Pract. 2012; 2012: 524325.

[39] Mitchell SE, Paasche-Orlow MK, Forsythe SR, et al. Post-discharge hospital utilization among adult medical inpatients with depressive symptoms. J Hosp Med. 2010 Sep; 5(7): 378-84. PMid:20577971 http://dx.doi.org/10.1002/jhm.673

[40] Greenwald JL, Denham CR, Jack BW. The hospital discharge: a review of a high risk care transition with highlights of a reengineered discharge process. J Patient Saf. 2007 Jun; 3: 97-106. http://dx.doi.org/10.1097/01.jps.0000236916.94696.12 